\title{
SOEP
}

SOEPpapers

SOEPnONOErs
on Multidisciplinary Panel Data Research
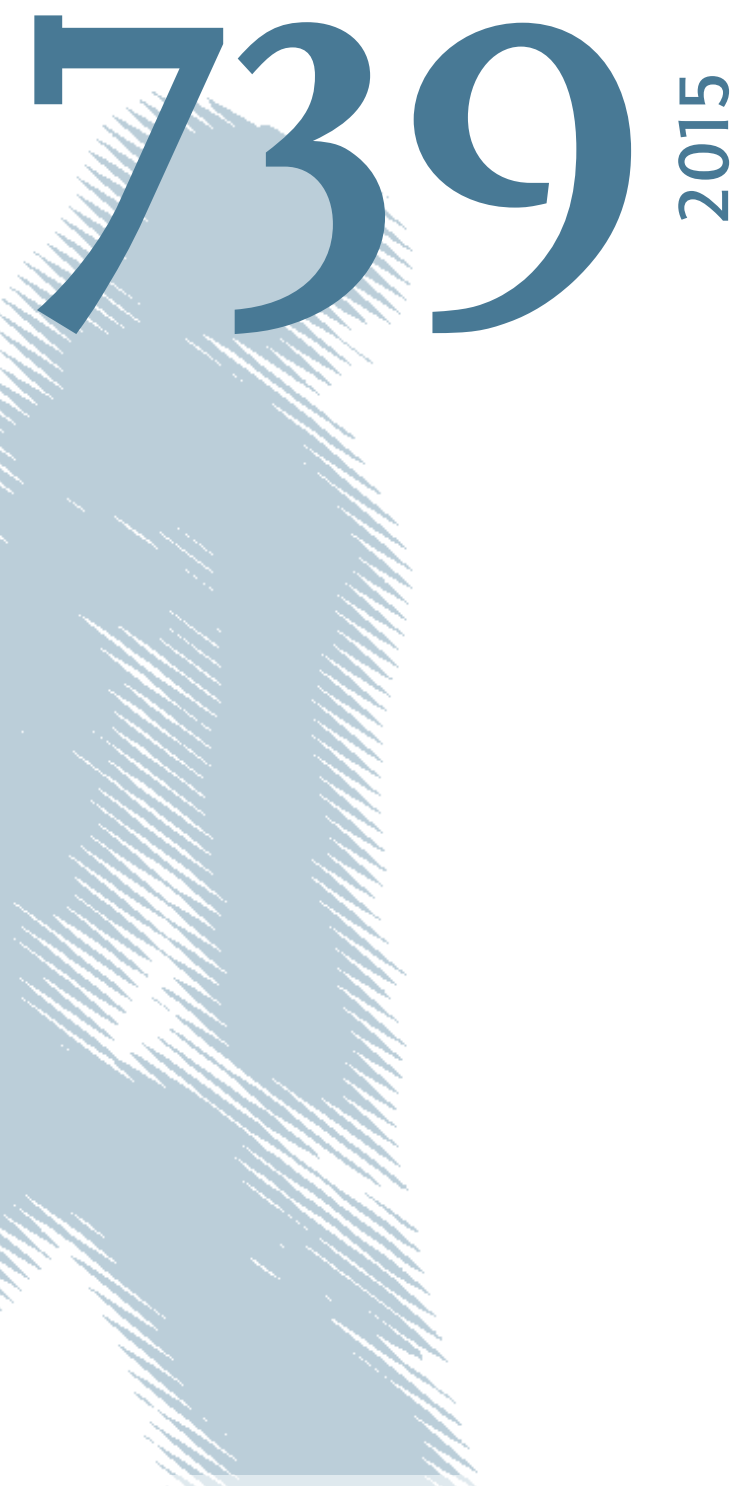

\section{Poverty Profiles and Well-Being: Panel Evidence from Germany}

Andrew E. Clark, Conchita D'Ambrosio, Simone Ghislandi 
This series presents research findings based either directly on data from the German SocioEconomic Panel study (SOEP) or using SOEP data as part of an internationally comparable data set (e.g. CNEF, ECHP, LIS, LWS, CHER/PACO). SOEP is a truly multidisciplinary household panel study covering a wide range of social and behavioral sciences: economics, sociology, psychology, survey methodology, econometrics and applied statistics, educational science, political science, public health, behavioral genetics, demography, geography, and sport science.

The decision to publish a submission in SOEPpapers is made by a board of editors chosen by the DIW Berlin to represent the wide range of disciplines covered by SOEP. There is no external referee process and papers are either accepted or rejected without revision. Papers appear in this series as works in progress and may also appear elsewhere. They often represent preliminary studies and are circulated to encourage discussion. Citation of such a paper should account for its provisional character. A revised version may be requested from the author directly.

Any opinions expressed in this series are those of the author(s) and not those of DIW Berlin. Research disseminated by DIW Berlin may include views on public policy issues, but the institute itself takes no institutional policy positions.

The SOEPpapers are available at http://www.diw.de/soeppapers

\section{Editors:}

Jan Goebel (Spatial Economics)

Martin Kroh (Political Science, Survey Methodology)

Carsten Schröder (Public Economics)

Jürgen Schupp (Sociology)

Conchita D'Ambrosio (Public Economics)

Denis Gerstorf (Psychology, DIW Research Director)

Elke Holst (Gender Studies, DIW Research Director)

Frauke Kreuter (Survey Methodology, DIW Research Fellow)

Frieder R. Lang (Psychology, DIW Research Fellow)

Jörg-Peter Schräpler (Survey Methodology, DIW Research Fellow)

Thomas Siedler (Empirical Economics)

C. Katharina Spieß (Education and Family Economics)

Gert G. Wagner (Social Sciences)

ISSN: 1864-6689 (online)

German Socio-Economic Panel Study (SOEP)

DIW Berlin

Mohrenstrasse 58

10117 Berlin, Germany

Contact: Uta Rahmann | soeppapers@diw.de 


\title{
Poverty Profiles and Well-Being: Panel Evidence from Germany*
}

\author{
ANDREW E. CLARK \\ Paris School of Economics - CNRS \\ Andrew.Clark@ens.fr \\ CONCHITA D’AMBROSIO \\ Université du Luxembourg \\ DIW Research Professor \\ conchita.dambrosio@uni.lu \\ SIMONE GHISLANDI \\ Università Bocconi and Econpubblica \\ simone.ghislandi@unibocconi.it
}

This version: February 2015

\begin{abstract}
We consider the link between poverty and subjective well-being, and focus in particular on the role of time. We use panel data on 49,000 individuals living in Germany from 1992 to 2012 to uncover three empirical relationships. First, life satisfaction falls with both the incidence and intensity of contemporaneous poverty. Second, poverty scars: those who have been poor in the past report lower life satisfaction today, even when out of poverty. Last, the order of poverty spells matters: for a given number of years in poverty, satisfaction is lower when the years are linked together. As such, poverty persistence reduces well-being. These effects differ by population subgroups.
\end{abstract}

Keywords: Income, Poverty, Subjective well-being, SOEP.

JEL Classification Codes: I31, I32, D60.

\footnotetext{
* We thank participants at many seminars and conferences for valuable suggestions. The German data used in this paper were made available by the German Socio-Economic Panel Study (SOEP) at the German Institute for Economic Research (DIW), Berlin: see Wagner et al. (2007). Neither the original collectors of the data nor the Archive bear any responsibility for the analyses or interpretations presented here. Conchita D'Ambrosio gratefully acknowledges financial support from the Fonds National de la Recherche Luxembourg. This work was also supported by the French National Research Agency, through the program Investissements d'Avenir, ANR-10-LABX-93-01.
} 


\section{Introduction}

The relationship between individual income and subjective well-being has been a mainstay of empirical work, both within and across countries, and both at a single point in time and over time. The general consensus from this existing work is that: 1) at a given point in time within each country, the richer are more satisfied with their lives than the poorer, with additional income increasing satisfaction at a decreasing rate; 2) within each country over time, rising average income often does not seem to substantially increase life satisfaction; and 3) across countries, on average, individuals living in richer countries are more satisfied with their lives than are those living in poorer countries (see, amongst a vast number of others, Blanchflower and Oswald, 2004, Clark et al., 2008b, Diener and Biswas-Diener, 2002, Di Tella and MacCulloch, 2006, Easterlin, 1995, Frey and Stutzer, 2002, and Senik, 2005).

While there is now something like agreement with respect to most of the above, it is noteworthy that work in this domain in the burgeoning subjective well-being literature has been resolutely atemporal (whereby some measure of current well-being is related to current income), with relatively few exceptions that we will discuss below. However, at the same time, a considerable amount of recent work in various fields of economics has underlined the importance of the past as a determinant of today's outcomes and individual behaviours.

Our aim here is to combine two flourishing literatures, one on poverty and the other on subjective well-being. We consider a number of different relationships between poverty and subjective well-being, and emphasise the role of time. We first focus on the contemporaneous relationship between income poverty and life satisfaction. Although it is well known that richer individuals are more satisfied with their lives, no existing work has, to the best of our knowledge, analysed income poverty per se. We show that selfreported satisfaction with life is indeed lower for those who are classified as being in poverty. As might be expected, not only the fact of being in poverty, but also its intensity (i.e. the relative distance from the poverty line) affects subjective well-being.

In terms of current individual well-being, there are a number of possible different ways in which time may matter. The first way in which the past affects the present is via the consequences of completed past events. Take for example unemployment. Here, the 
well-being of the currently employed may be lower if they have experienced unemployment in the past, with this negative effect reflecting either anticipated future unemployment spells (unemployment begets unemployment) or lower contemporaneous earnings. This phenomenon is often called 'scarring' in the labour economics literature. Analogously, a past experience of poverty may still continue to scar the individual even after they have moved out of poverty. In this respect, Cappellari and Jenkins (2004, p.598) note that "the experience of poverty itself might induce a loss of motivation, lowering the chances that individuals with given attributes escape poverty in the future". Along these lines, our second contribution is to consider the well-being effect of past completed poverty spells, and conclude that poverty scars: past episodes of poverty significantly reduce current life satisfaction.

Last, we refer to recent work in the deprivation literature on sequences of poverty spells. The broad question that is asked here is: Given a number of years spent in poverty, is it worse to spend these in one long spell or a larger number of shorter-duration spells? The former is said to represent more persistent poverty. We here show that persistent poverty is worse: past years of poverty that were linked together to a greater extent have an additional depressive effect on current well-being.

These effects differ across population subgroups. In particular, time seems to matter much less in general for older individuals: poverty does not scar for this group, nor does the persistence of poverty affect well-being.

The remainder of the paper is organised as follows. Section 2 proposes a brief review of poverty measurement, while Section 3 considers some of the work on time in economics, and in particular with respect to subjective well-being. Section 4 then describes the SOEP panel data that we use, and the results appear in Section 5. Last, Section 6 concludes.

\section{Measuring Poverty}

The seminal contribution to poverty measurement is Sen (1976), who distinguishes two fundamental issues: (i) identifying the poor in the population under consideration; and (ii) constructing an index of poverty using the available information on the poor. 
The first problem has been dealt with in the literature by setting a poverty line and identifying as poor all individuals with incomes below this threshold. The way in which this poverty line is determined remains very much debated and differs considerably between countries (for an extensive survey see World Bank, 2005, Chapter 3). In this paper we follow the European Union approach, in which the poverty line equals $60 \%$ of the national median equivalent income (see Section 4 for details).

Regarding the second issue, the aggregation problem, many indices have been proposed which capture not only the fraction of the population that is poor or the incidence of poverty (the headcount ratio), but also the extent of individual poverty and inequality amongst those who are poor. We here follow the approach proposed by Foster et al. (1984).

Let $x=\left(x_{1}, x_{2}, . . x_{n}\right)$ be the distribution of income among $n$ individuals, where $x_{i} \geq 0$ is the income of individual $i$. For expositional convenience we assume that the income distribution is non-decreasingly ranked, that is, for all $x, x_{1} \leq x_{2} \leq \ldots \leq x_{n}$. We denote the poverty line by $z$. For any income distribution, $x$, individual $i$ is said to be poor if $x_{i}<z$. The normalised deprivation of individual $i$ who is poor with respect to $z$ is given by their relative shortfall from the poverty line, i.e.

$$
d_{i}^{\alpha}=\left(\frac{z-x_{i}}{z}\right)^{\alpha}
$$

where $\alpha \geq 0$ is a parameter. When $\alpha=0$, the only dimension of poverty which counts is its incidence, as normalised deprivation is equal to one for all of the poor. When $\alpha=1$, normalised deprivation also reflects the intensity of poverty with a higher value of $d$ being assigned to poorer individuals. The normalised deprivation score for the rich, those whose incomes (weakly) exceed $z$, is always set equal to zero.

The literature on poverty measurement has advanced to a considerable degree of sophistication since Sen (1976). However, the explicit inclusion of time has not been at the forefront of these developments. Only recently have a number of measures of intertemporal poverty been proposed, as opposed to indices where attention is limited to a single-period. The Journal of Economic Inequality recently published a special issue on 
measuring poverty over time, the introduction to which (Christiaensen and Shorrocks, 2012) provides an exhaustive summary of the literature.

Various approaches exist for the measurement of poverty over time. Without going into specifics, it may be useful to distinguish the persistence of poverty from what we think of as being in chronic poverty. Generally speaking, we think of chronic poverty as applying to a situation in which an individual is in poverty for a considerable number of the time periods under consideration. This does not however necessarily mean that any attention is paid to the durations of unbroken poverty spells, given the total number of periods spent in poverty. To illustrate, if an individual is poor for six periods out of ten, say, does it matter if these six periods occurred consecutively, or in two blocks of three periods, or three blocks of two periods? The notion of persistence to which we appeal here explicitly takes the continuity of poverty spells into consideration. Chronic poverty then refers to the frequent occurrence of poverty, while persistent poverty requires, in addition to frequency, that poverty be manifested in periods that are more linked together. Our empirical analysis will apply the measure of chronic poverty of Foster (2009), while the index of persistent poverty is that proposed by Bossert et al. (2012).

Let $d_{i t}$ be the normalised deprivation of the poor individual $i$ in period $t$. These normalised deprivations are raised to the power $\alpha \in\{0,1\}$ and are collected in a $T$ dimensional vector. When $\alpha=0$, the vector is a list of ones and zeros, where a one indicates a period in poverty and zero a period out of poverty. For example, over a period of five years $(1,1,1,0,1)$ indicates that the individual spent the first three periods in poverty, one period out of poverty and then returned to poverty in the final period. The first spell of poverty is of length 3 while the last is of length 1 . Similarly, $(1,1,0,1,1)$ indicates that the individual spent the first two periods in poverty, one period out of poverty and then returned to poverty for two additional periods. Both spells of poverty in this second case are of length two. The index of individual poverty persistence proposed by Bossert et al. (2012) weights each spell by its length, $l$. It is the weighted average of the individual normalised deprivation scores where, for each period, the weight is given by the length of the spell to which this period belongs:

$$
B C D_{i}^{\alpha}=\frac{1}{T} \sum_{t=1}^{T} I^{t}\left(d_{i t}\right)^{\alpha},
$$


with $\alpha \geq 0$ being a parameter.

For the first example given above, $(1,1,1,0,1)$, the index value is $B C D_{i}^{0}=\frac{1}{5}(3(1+1+1)+1 \cdot 0+1 \cdot 1)=\frac{10}{5}$. For the second example, $(1,1,0,1,1)$, the index value is $B C D_{i}^{0}=\frac{1}{5}(2(1+1)+1 \cdot 0+2(1+1))=\frac{8}{5}$. The BCD index then does more than simply count the number of periods in which the individual is poor (which are the same in both examples). When $\alpha=0$, the index captures the incidence of persistent poverty while when $\alpha=1$ the depth of poverty is also taken into account.

In the empirical application below using subjective well-being data, we will normalise this index to values between $[0,1]$ by dividing the values above by $T$, the total number of years.

The index of chronic poverty we use in this paper is that proposed by Foster (2009), which is simply the average poverty that an individual has experienced over time, that is:

$$
F_{i}^{\alpha}=\frac{1}{T} \sum_{t=1}^{T}\left(d_{i t}\right)^{\alpha}
$$

with $\alpha \geq 0$ being a parameter. When $\alpha=0$ we measure the average incidence of poverty the individual faced, while when $\alpha=1$ we calculate the average relative shortfall from the poverty line over all of the periods for which the individual is observed.

\section{Some Existing Literature and Our Hypotheses}

It is well known that many subjective well-being measures are left-skewed, so that many people report quite high scores, and that on average richer individuals are more satisfied with their lives than are the less rich: a useful recent summary using Gallup World Poll data is Diener et al. (2010). However, almost no work, to the best of our knowledge, has considered income poverty as such as a determinant of satisfaction with life in a multivariate setting. Following Clark et al. (2014), we here first look at the

effects of both being poor and poverty intensity ( $d^{0}$ and $d^{1}$ in the terminology above). Drawing on the recent literature on measuring poverty over time, we also include 
measures of the poverty that the individual has experienced in the past ( $F$ and $B C D$ in the terminology above) as determinants of their current well-being.

The central role of the past in determining today's outcomes and behaviours can be found in a number of recent contributions across a variety of fields in economics. In the finance literature, past personal experience has been shown to be a key determinant of current investor behaviour (see, among others, Kaustia and Knüpfer, 2008, and Malmendier and Nagel, 2011). There is also an effect of the past on attitudes in general. Fernández et al. (2004), for example, argue that the growing number of men brought up in a family in which the mother worked has been a significant factor in the increase in female labour-force participation over time. This transmission has also been noted with respect to educational outcomes (see, among others, Rosenzweig and Wolpin, 1994, and Behrman et al., 1999).

This past personal experience need not only be within the household. When these past experiences are at some aggregate level, the problem of causality over time is alleviated (my current risk-aversion, for example, cannot have caused the regional unemployment rate when I was growing up). Some well-known examples of such transmission include Alesina and Fuchs-Schündeln (2007), who show that East Germans (presumably as a result of their history) are currently more pro-redistribution than are West Germans. Blanchflower and Freeman (1997) equally use data from the 1987 and 1992 International Social Survey Program surveys to consider the distribution of incomes across occupations that respondents consider as fair. One of their main results is that the income distribution considered to be fair by respondents in ex-Communist countries is tighter than that of respondents in Western countries (but that this gap has narrowed over time).

Regarding the labour market, Giuliano and Spilimbergo (2014) explicitly use the arrow of time and consider the role of economic growth experienced during the ages of 18 and 25 on the individual's current beliefs regarding fairness in the US General Social Survey. Blake (2012) appeals to a battery of indicators of the individual's environment between birth and the age of 16 (parental unemployment, household financial situation, and the regional GDP growth rate), and shows, using US Health and Retirement Survey data, that some of these significantly predict both current beliefs (regarding the 
individual's perception of the likelihood of future recession, and of own personal job loss) and risk-related behaviours (investment in shares, and the making of a will).

Last, some relatively new work has appealed to cohort data, in which individuals (or their parents) are repeatedly interviewed over periods of many decades (a longer period than even the longest available panel data allows), to show how factors present at childbirth relate to outcomes at very young ages, which in turn feed through to outcomes at adolescence, and so on all the way up to outcomes when the individual is in their 30s or 40s. Two such examples are Frijters et al. (2014) and Layard et al. (2014).

We here want to analyse the relationship between income and subjective wellbeing, taking the past into account. But we do not want to consider all incomes as equal, as it were: we are particularly interested in the well-being repercussions of poverty. While we suspect that there is a relationship between income and subjective well-being at all levels of income, there is no guarantee that this relationship be the same across the income distribution. In particular, poverty is a complex phenomenon which affects all of the psychological, social and economic dimensions of an individuals' life, and it is unclear whether its relationship to subjective well-being can be inferred from the general analysis of income. As in Clark et al. (2014), our first question here then explicitly considers the relationship between both the incidence and intensity of current income poverty and current well-being.

We also take into account the mediating role of time. As opposed to Clark et al. (2014), where the focus is on adaptation within the poverty spell, we next ask what happens to individual well-being once the poverty spell is over, i.e. the individual is no longer poor. Carrying on with our unemployment example, does the fact of having had an unemployment spell in the past reduce the current level of well-being when back in work? If so, past exposure can have ongoing current effects, even when the past spell is over. This kind of 'scarring' effect was originally used in labour economics to refer to the effects of past (involuntary) unemployment on current labour-market earnings (see Ruhm, 1991, for example). More recent incarnations of this literature have asked whether past unemployment reduces the current well-being of individuals. Work on the SOEP (Clark et al., 2001) does find evidence of such a correlation. It is an open question as to why such scarring effects occur. Knabe and Rätzel (2011) also appeal to SOEP data to 
argue that scarring may come about via future expectations: past exposure to a negative event may make individuals more scared of its future reappearance, a finding which has been re-examined in European Social Survey data by Lange (2013). We will here consider whether past poverty exposure affects current subjective well-being, ceteris paribus.

Our third question considers the sequence of exposure to poverty. While about $15 \%$ of the individuals considered here will have experienced poverty in at least one year (i.e. they live in households that were defined as being poor when the interview was carried out), their exposure to poverty differs markedly. Some will have been poor in only one year, others will have been poor in many years. And amongst the latter, some households will have been poor continuously for a number of years, while others will have moved in and out of poverty. We will here pick up both of these phenomena: the number of years the household has been poor and the extent to which their poverty years are linked together. In particular we will ask whether, for a given number of poverty years, subjective well-being is lower when the spells are linked together. If this is the case, poverty persistence reduces well-being. ${ }^{1}$

\section{Data and Methods}

Our empirical analysis of the link between poverty and subjective well-being is carried out using one of the most extensively-used panel datasets in the subjective wellbeing literature, the German Socio-Economic Panel (SOEP). The SOEP is an ongoing panel survey with a yearly re-interview design (see http://www.diw.de/gsoep). The starting sample in 1984 was almost 6,000 households based on a random multi-stage sampling design. A sample of about 2,200 East German households was added in June 1990, half a year after the fall of the Berlin wall. This gives a very good picture of the GDR society on the eve of the German currency, social and economic unification which took place on July $1^{\text {st }} 1990$. In 1994-95 an additional subsample of 500 immigrant households was included to capture the massive influx of immigrants since the late

\footnotetext{
${ }^{1}$ This is not an exhaustive list of the ways in which the past can affect the present. We can also think of the manner in which well-being changes within a specific unemployment or poverty spell, as in the literature on adaptation. It can also be the case that the variance of past events affects current well-being, as in Bossert and D'Ambrosio (2013), or some other combination of past values, as in the peak-end theory of Redelmeier and Kahneman (1996).
} 
1980s. An oversampling of rich households was added in 2002, improving the quality of inequality analyses, especially at the upper end of the distribution. Finally, in 1998, 2000, 2006 and 2011 four additional representative random samples were added, boosting the overall number of interviewed households in the 2011 survey year to about 12,300, covering approximately 21,000 individuals aged over 16 .

Our analysis sample covers the period 1992 (the first wave of data for which annual income information is available for the East German sample) to 2012. The initial sample consists of all adult respondents with valid information on income and life satisfaction, leaving us with approximately 368,000 observations based on about 49,000 individuals in East and West Germany.

The individual income measure we employ for most of our analyses is annual equivalent household income. We here control for differences in household size and therefore economies of scale by applying an equivalence scale with an elasticity of 0.5 , given by the square root of household size. The poverty line in every year is set at $60 \%$ of the country-level median equivalent household income. An individual is poor if the income of her household is below this value. This is the standard definition of poverty applied in Europe and all official EU documents. We do below run a series of robustness checks where poverty lines are defined according to different percentage figures.

Our dependent well-being measure, life satisfaction, is measured on an 11-point scale. Subjects were asked the following question: "In conclusion, we would like to ask you about your satisfaction with your life in general, please answer according to the following scale: 0 means completely dissatisfied and 10 means completely satisfied: How satisfied are you with your life, all things considered?" The life satisfaction score for individual $i$ in year $t$ is denoted below by $w b_{i t}$.

Our regression analyses will control for age (eight age groups, from 16-20 to 80+ years old), marital status (separated, single, divorced, widowed), whether employed, residency in East or West Germany, years of education, and number of children in the household. Since we run fixed-effect specifications, no time-invariant variables such as sex and immigration status appear in the regression. Year dummies are included but the coefficients are not reported. 
In order to better account for heterogeneity, the analysis is performed first for the entire population and then for subgroups by gender and age. For the latter, we cut the sample at age 60. These population partitions are inspired by work showing that life satisfaction and adaptation to various life events differ by age and sex (see, for example, Clark et al., 2008a).

The descriptive statistics of our main sample appear in Table 1 and Figure 1. Our 368,000 observations correspond to around 49,000 subjects, who are thus observed on average between seven and eight years each. The majority of the sample is of working age and is either married (61\%) or single (24\%). Approximately 58\% of the sample is employed at the moment of the survey. In Table 1, 12\% of observations correspond to respondents whose equivalent income was below $60 \%$ of the yearly median income that year: these are the observations corresponding to the poor in our empirical analysis. The average value of our dependent variable, life satisfaction, is close to seven on the zero to ten scale, so that we do not seem to suffer too much from bunching at the top end of the scale. Life satisfaction is strongly correlated with age, showing in Figure 1 the typical Ushape followed by a subsequent drop for the over 65s. It is difficult to disentangle cohort from age effects; however, our regression analysis will control for individual fixedeffects.

The distribution of poverty by age and gender does not exactly mirror that of life satisfaction. Poverty prevalence is completely U-shaped in age. This is as expected, as earnings tend to peak in the 50s and retirement is typically associated with sharply lower real incomes. However, Figure 1 does suggest that life satisfaction and poverty are related. This is confirmed by the data. Well-being scores of zero to two are reported by $2 \%$ of the sample, $27 \%$ of whom are in poverty; the analogous figures for well-being scores of eight to ten are $40 \%$ and $7 \%$ respectively.

Throughout the paper, in order to make full use of the panel nature of our data, and in line with most of the literature on well-being, we use fixed-effects estimation. This allows us to control for otherwise unobserved individual characteristics and any potentially different use of the underlying satisfaction scale across individuals. The general model then takes the form: 


$$
w b_{i t}=\alpha_{i}+\gamma_{t}+\beta C_{i t}+\theta P I_{i t}+\epsilon_{i t}
$$

where $C_{i t}$ is the set of time-varying individual covariates and $P I_{i t}$ a series of poverty indices at the individual level. Depending on the question addressed, both the sample and the form of the $P I_{s}$ will change. With the fixed effect in [4], $\alpha_{i}$, the estimated coefficients on both $C_{i t}$ and $P I_{i t}$ are identified from within-subject changes in these variables over time. We therefore run "within" fixed-effect linear regressions.

We first establish the relationships between both the incidence and intensity of contemporaneous poverty and life satisfaction: these turn out, unsurprisingly, to be negative. We then introduce time explicitly, and ask whether poverty has a scarring effect on well-being, that is if the life satisfaction of those who are currently out of poverty is lower if they have been poor in the past. Last, we consider the role of persistence, whereby the order of poverty spells matters: For a given number of poverty years, is satisfaction lower when these years are joined together?

\section{Results}

We present our three main results in the first three sub-sections below, followed by a fourth sub-section addressing the issue of the definition of the poverty line.

\subsection{Current poverty incidence and intensity}

This section borrows from Clark et al. (2014). We start with the simplest question: the effect of contemporaneous poverty on subjective well-being. Table 2 shows the results from fixed-effect regressions of life satisfaction, in which the estimates refer to within-subject variation.

The regressions include various control variables, which attract the expected coefficients: life satisfaction is U-shaped in age, at least up until age 80. The U-shape seems sharper for women than for men. Education attracts a positive significant but small coefficient in the overall sample, although it is worth remembering that many individuals will not change their years of education over time. Those who marry are more satisfied, while widowhood and separation are associated with lower life satisfaction, especially for women. The divorced are estimated to be more satisfied in this fixed-effects regression, 
which is consistent with higher well-being as compared to a failing marriage (these are within-subject regressions). This positive effect is found for male and younger respondents. ${ }^{2}$ With respect to labour-force status, we find a positive estimated coefficient, as expected, for employment.

At the top of Table 2, both the incidence $\left(d^{0}\right)$ and intensity $\left(d^{1}\right)$ of poverty are significantly negatively correlated with life satisfaction. This is true also within each subgroup. The estimated effect of poverty in Table 2 is large in size. An individual living in a household that is just below the poverty line (so that $d^{0}=1$ and $d^{1}$ is almost zero) has a life satisfaction score that is 0.132 points lower than the same individual in the same household when that household is not poor; this effect is of the same magnitude as the happiness boost from marriage.

\subsection{Scarring}

The above section established that contemporaneous poverty and well-being are correlated. We now introduce time, and ask whether past poverty has a scarring effect on well-being. We do so by including a dummy into the regression which indicates whether an individual has experienced poverty in the past. Since individuals who are observed for shorter periods may not provide evidence of the medium-/long-run effect we are interested in, we only consider in this analysis individuals who are observed for at least ten years (although any time restriction we introduce here actually does not particularly affect the qualitative results).This estimation approach will introduce some bias if individuals leave the survey precisely because they have become poor. However, this is not the case in our panel: poverty incidence is the same for both the excluded and included samples.

The results appear in Table 3. Conditional on current poverty, past poverty experience reduces current life satisfaction: poverty is not then ephemeral but has wellbeing effects that extend beyond the end of the poverty spell. The overall negative coefficient in column 1 of Table 3 seems to be driven mainly by women and those aged 60 and under. The experience of past poverty is not significant for older respondents

\footnotetext{
${ }^{2}$ The positive effect of divorce on life satisfaction over time in SOEP data in Clark et al. (2008a) is notably higher for men than for women.
} 
(although this is arguably due to a larger standard error, as the estimated coefficient is similar to that for the younger group).

\subsection{Chronic and persistent poverty}

The last question we wish to address also relies on the notion of time with respect to the impact of poverty on subjective well-being. Instead of looking at the simple existence of a past poverty spell, as above, we here take into account the individual's entire cumulated experience of poverty. In this context, we not only consider the past number of years spent in poverty (which reflects chronic poverty, as discussed in Section 2 ), but also ask whether a given number of poverty years reduce well-being more if they are consecutive (which picks up the separate effect of the persistence of poverty).

Our last regression then includes both lagged average past cumulative poverty, given by the Foster index (measuring chronicity, or the frequency of poverty, equation [3]), and the normalised Bossert et al. index (measuring persistence, BCD in equation [2]), both calculated over all of the past years, excluding the current year. The results presented here refer to the incidence of poverty for both indices (L.Foster ${ }^{0}$ and L.BCD ${ }^{0}$, where L stands for "lagged"), as the results are arguably simpler to interpret (although very similar results pertain if we instead use L.Foster ${ }^{1}$ and L.BCD ${ }^{1}$ ). As can be seen from equation [2], the BCD persistence index mechanically includes chronicity. In order to disentangle the two, our regressions introduce both L.Foster ${ }^{0}$ and the difference L. $\left(\right.$ Foster $\left.^{0}-B C D^{0}\right)$ as explanatory variables. This second term then picks up persistence conditional on any effect of chronic poverty. If past poverty persistence reduces current life satisfaction, we expect to find a positive estimated coefficient on this difference variable. As was the case in Section 5.2 above, we only include in our regressions individuals who are observed in the SOEP for at least 10 years.

The results in Table 4 clearly show that the chronicity of poverty, as measured by the Foster index, matters. Chronic poverty attracts a negative coefficient in all of the columns, although the statistical significance varies. Male life satisfaction is not significantly correlated with the cumulative number of years spent in poverty, although as we will see below, men are significantly affected by poverty persistence. 
The sign of the estimated coefficient on L.(Foster $\left.{ }^{0}-B C D^{0}\right)$ is always positive, as expected. The sequence of a given number of poverty years thus matters, with years of poverty that are more consecutive being worse: a succession of shorter exposures in the past has a less-negative effect on current well-being than does one longer exposure. In the overall sample, the associated coefficient is positive and significant at the ten per cent level. In the sub-regressions, poverty persistence is insignificant for women and the elderly, but matters for men and those aged up to 60. For women then the chronic dimension of poverty counts more than its persistence, while for men it is the other way round. In both cases, however, previous poverty clearly affects current well-being.

It is worth underlining that the introduction of this combination of all of these indices together in one regression asks quite a lot of the data. In our fixed-effects regressions, our coefficients of interest are identified by changes over the different waves of the SOEP, for the same individual, in the values of both past poverty incidence $\left(\right.$ L.Foster ${ }^{0}$ ) and persistence $\left(\mathrm{L} . B C D^{0}\right)$. To check whether having both L.Foster ${ }^{0}$ and L. $\mathrm{BCD}^{0}$ is indeed asking too much of the data, we can produce versions of Table 4 including only L.Foster ${ }^{0}$ or only L.BCD ${ }^{0}$. This yields consistent results, with the coefficients on these indices always being negatively and significantly correlated with well-being, except for the elderly.

\subsection{Do the results depend on the choice of the poverty line?}

One concern with the above analysis is the choice of the "right" poverty line. In line with EU practice we have considered the relative poverty line given by $60 \%$ of the median of the distribution of equivalent income. Although this is a very common assumption, it can easily be argued that this line is too high or too low: especially as we are here interested in individuals feeling, rather than objectively being, poor. A poverty line that is too high will "dilute” poverty's impact, by defining as poor some individuals who do not see themselves as such (and, consequently, may not report lower well-being); a line that is too low conversely assigns some people who are poor (and unhappy) to the non-poor group.

As it is difficult to be sure a priori which definition is the best, we re-ran our analyses with different poverty lines. Specifically, we set the poverty line equal to a 
changing percentage (40\%, 50\%, $70 \%$ and $80 \%$ ) of the median income. The estimated coefficients on our main variables of interest appear in Table 5.

The negative and significant effect of contemporaneous poverty (incidence and intensity) on life satisfaction prevails in all cases (and is not shown in the table for space reasons). The past continues to count significantly, except at the extreme values. Specifically, scarring always attracts a negative significant estimated coefficient in the overall sample, except when the poverty line is $40 \%$. In a sense this is understandable, as lower poverty lines progressively eliminate poverty spells, meaning we end up with less variance (especially within individual) in our data. In the subgroups, women and those under 60 are more sensitive to past poverty, as in Table 3.

With respect to chronic and persistent poverty, we lose significance on the latter (but not the former) poverty line in the overall sample. At the $80 \%$ poverty line, neither of the past poverty measures (L.Foster ${ }^{0}$ and L.BCD $^{0}$ ) are significant in the overall sample, although they continue to occasionally be so in the sub-samples (for women and the younger sample). A high poverty line does then seem to dilute the effect of poverty on well-being as far as this aspect of the past is concerned.

\section{Conclusion}

We have here used long-run panel data to analyse the effects of poverty on individual well-being, taking individual fixed effects into account. We show that both the incidence and intensity of poverty reduce life satisfaction. Our main results relate to the effect of time. We find that past poverty scars current well-being. In addition, the sequence of poverty spells matters. For the same number of years of poverty exposure, life satisfaction is lower when all of the poverty years are joined together rather than split up into periods in and out of poverty. This ties in with the idea that individuals may have the resources (financial or otherwise) to deal with relatively short-run poverty periods, but not poverty that lasts too long. Periods out of poverty may allow individuals to replenish these resources (as suggested by Dutta et al., 2013), so that movements in and out of poverty are not as bad as one uninterrupted poverty spell.

We believe that these results are important in at least two ways. First, they represent new information on the relationship between poverty and subjective well-being 
explicitly taking the past into account. We have shown that both current and past poverty matter, even in a rich country. Second, we have provided a bridge between theory and empirics, by showing that the most recent literature on poverty indices can be applied to well-known panel data to see which dimensions of poverty are the most salient. Future research may well consider taking a similar line with the vast number of different indices which are now available in the theoretical literature. 


\section{References}

Alesina, A., and N. Fuchs-Schündeln, (2007), “Good-Bye Lenin (or Not?): The Effect of Communism on People's Preferences,” American Economic Review, 97, 1507-1528.

Behrman, J., A. Foster, M. Rosenzweig and P. Vashishtha, (1999), "Women's Schooling, Home Teaching, and Economic Growth,” Journal of Political Economy, 107, 682-714.

Blanchflower, D.G., and R.B. Freeman, (1997),“The Attitudinal Legacy of Communist Labor Relations”. Industrial and Labor Relations Review, 50, 438-459.

Blanchflower, D.G. and A.J. Oswald, (2004), "Well-Being over Time in Britain and the USA,” Journal of Public Economics, 88, 1359-1386.

Blake, H., (2012), "How Do Recession and Unemployment Impact Children in the Long Term?,” PSE, mimeo.

Bossert, W. and C. D’Ambrosio, (2013), “Measuring Economic Insecurity”, International Economic Review, 54, 1017-1030.

Bossert, W., C. D’Ambrosio and S.R. Chakravarty, (2012), “Poverty and Time,” Journal of Economic Inequality, 10, 145-162.

Burchardt, T., (2005), “Are One Man’s Rags Another Man’s Riches? Identifying Adaptive Expectations Using Panel Data,” Social Indicators Research, 74, 57-102.

Cappellari, L. and S.P. Jenkins, (2004), "Modelling low income transitions," Journal of Applied Econometrics, 19, 593-610.

Christiaensen, L. and T. Shorrocks, (2012), “Measuring Poverty Over Time,” Journal of Economic Inequality, 10, 137-143.

Clark, A.E., C. D'Ambrosio and S. Ghislandi, (2014),“Adaptation to Poverty in LongRun Panel Data”. PSE, mimeo. 
Clark, A.E., E. Diener, Y. Georgellis and R.E. Lucas, (2008a), "Lags and Leads in Life Satisfaction: a Test of the Baseline Hypothesis,” Economic Journal, 118, F222-F243.

Clark, A.E., P. Frijters and M. Shields, (2008b), "Relative Income, Happiness and Utility: An Explanation for the Easterlin Paradox and Other Puzzles," Journal of Economic Literature, 46, 95-144.

Clark, A.E., Y. Georgellis and P. Sanfey, (2001), "Scarring: the Psychological Impact of Past Unemployment,” Economica, 68, 221-241.

Diener, E. and R. Biswas-Diener, (2002), "Will Money Increase Subjective Well-Being? A Literature Review and Guide to Needed Research,” Social Indicators Research, 57, 119-169.

Diener, E., W. Ng, J. Harter and R. Arora, (2010), "Wealth and Happiness Across the World: Material Prosperity Predicts Life Evaluation, Whereas Psychosocial Prosperity Predicts Positive Feeling," Journal of Personality and Social Psychology, 99, 52-61.

Di Tella, R. and R. MacCulloch, (2006), "Some Uses of Happiness Data in Economics," Journal of Economic Perspectives, 20, 25-46.

Dutta, I., L. Roope and H. Zank, (2013),“'On intertemporal poverty measures: the role of affluence and want," Social Choice and Welfare 41, 741-762.

Easterlin, R.A., (1995), "Will raising the incomes of all increase the happiness of all?," Journal of Economic Behavior and Organization, 27, 35-48.

Fernández, R., A. Fogli and C. Olivetti, (2004), "Mothers and Sons: Preference Formation and Female Labor Force Dynamics," Quarterly Journal of Economics, 119, 1249-1299.

Foster, J.E., (2009), “A Class of Chronic Poverty Measures,” in: T. Addison, D. Hulme and R. Kanbur, eds., Poverty dynamics: interdisciplinary perspectives, Oxford, Oxford University Press, 59-76. 
Foster, J., J, Greer and E. Thorbecke, (1984), “A Class of Decomposable Poverty Measures,” Econometrica, 81, 761-766.

Frey, B.S. and A. Stutzer, (2002), Happiness and Economics: How the Economy and Institutions Affect Human Well-Being, Princeton, Princeton University Press.

Frijters, P., D. Johnston, and M. Shields, (2014),“Does Childhood Predict Adult Life Satisfaction? Evidence from British Cohort Surveys,” Economic Journal, 124, F688F719.

Giuliano, P., and A. Spilimbergo, (2014),“Growing Up in a Recession,” Review of Economic Studies, 81 787-817.

Kaustia, M. and S. Knüpfer, (2008), "Do Investors Overweight Personal Experience? Evidence from IPO Subscriptions,” Journal of Finance, 63, 2679-2702.

Knabe, A. and S. Rätzel, (2011), "Scarring or Scaring? The Psychological Impact of Past Unemployment and Future Unemployment Risk,” Economica, 78, 283-293.

Lange, T., (2013), "Scarred from the Past or Afraid of the Future? Unemployment and Job Satisfaction across European Labour Markets," International Journal of Human Resource Management, 24, 1096-1112.

Layard, R., A.E. Clark, F. Cornaglia, N. Powdthavee, and J. Vernoit, (2014),"What Predicts a Successful Life? A Life-Course Model of Wellbeing,” Economic Journal, 124, F720- F738.

Malmendier, U. and S. Nagel, (2011), "Depression Babies: do Macroeconomic Experiences Affect Risk-taking?”Quarterly Journal of Economics, 126, 373-416.

Redelmeier, D., and D. Kahneman, (1996), "Patients' memories of painful medical treatments: real-time and retrospective evaluations of two minimally invasive procedures”. Pain, 66, 3-8. 
Rosenzweig, M. and K. Wolpin, (1994), "Inequality among Young Adult Siblings, Public Assistance Programs, and Intergenerational Living Arrangements," Journal of Human Resources, 29, 1101-1125.

Ruhm, C.J., (1991), “Are Workers Permanently Scarred by Job Displacements?,” American Economic Review, 81, 319-24.

Sen, A.K., (1976), “Poverty: an Ordinal Approach to Measurement,” Econometrica, 44, 219-231.

Senik, C., (2005), "Income Distribution and Well-Being: What Can we Learn from Subjective Data?,” Journal of Economic Surveys, 19, 43-63.

Socio-Economic Panel (SOEP), data for years 1984-2012, version 29, SOEP, 2013, doi:10.5684/soep.v29.

Wagner, G., J. Frick and J. Schupp, (2007), “The German Socio-Economic Panel Study (SOEP) - Scope, Evolution and Enhancements,” Schmollers Jahrbuch, 127, 139-169.

World Bank, (2005), "Introduction to Poverty Analysis," the World Bank Institute, Washington, downloadable at:

http://siteresources.worldbank.org/PGLP/Resources/PovertyManual.pdf. 
Figure 1: Poverty and Well-being by gender and age.
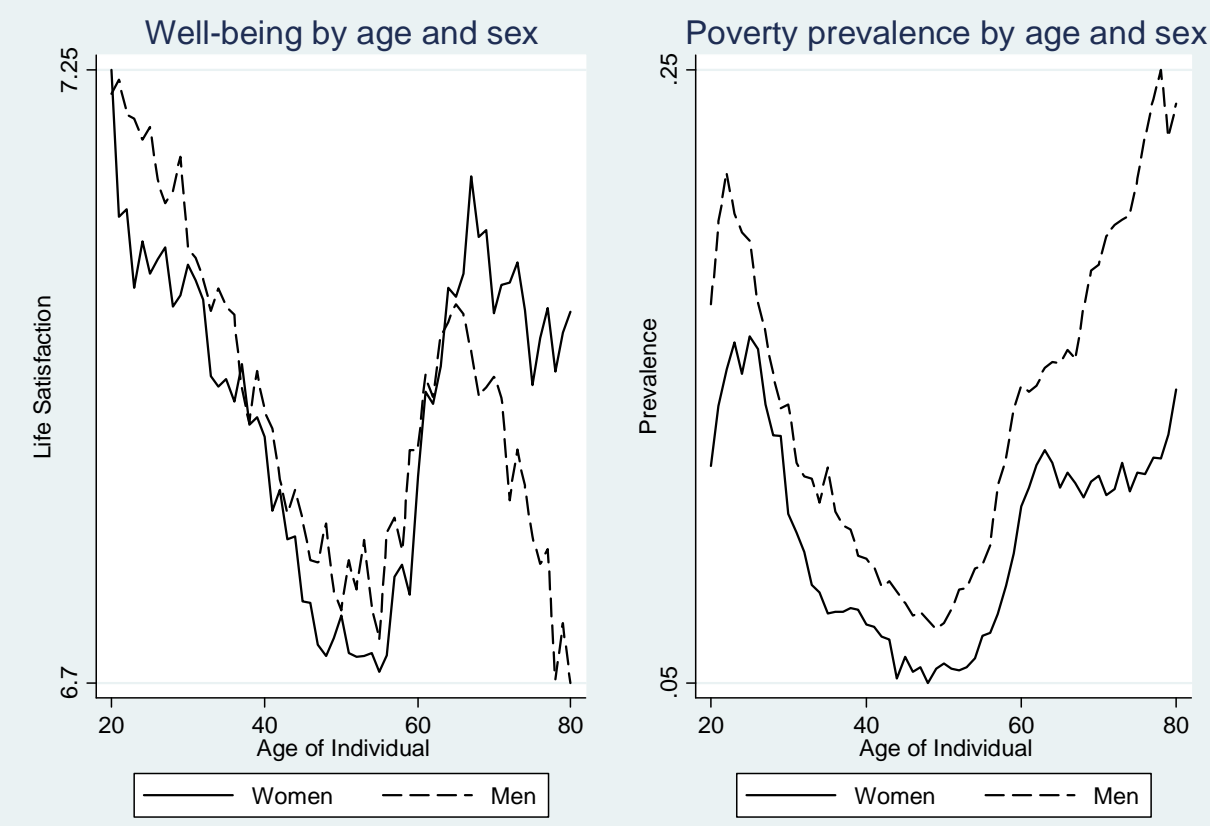

Note: Based on SOEP v29. 
Table 1: Descriptive Statistics in the Main Sample.

\begin{tabular}{|c|c|c|}
\hline Variable & Mean & Standard Deviation \\
\hline Life Satisfaction & 6.970 & 1.786 \\
\hline$d^{0}$ & 0.120 & 0.325 \\
\hline$d^{1}$ & 0.029 & 0.105 \\
\hline Foster $^{0}$ & 0.109 & 0.246 \\
\hline $\mathrm{BCD}^{0}$ & 0.074 & 0.224 \\
\hline Employed & 0.580 & 0.494 \\
\hline Age: 16-20 & 0.076 & 0.265 \\
\hline Age: $21-30$ & 0.153 & 0.362 \\
\hline Age: 31-40 & 0.180 & 0.397 \\
\hline Age: $41-50$ & 0.186 & 0.398 \\
\hline Age: $51-60$ & 0.161 & 0.374 \\
\hline Age: $61-70$ & 0.136 & 0.350 \\
\hline Age: 71-80 & 0.078 & 0.268 \\
\hline Age: 80-max & 0.026 & 0.159 \\
\hline Female & 0.513 & 0.500 \\
\hline No. Years of Education & 11.864 & 2.645 \\
\hline Married & 0.609 & 0.487 \\
\hline Single & 0.240 & 0.427 \\
\hline Widowed & 0.065 & 0.248 \\
\hline Divorced & 0.067 & 0.251 \\
\hline Separated & 0.017 & 0.130 \\
\hline No. children in $\mathrm{HH}$ & 0.577 & 0.928 \\
\hline East Germany & 0.223 & 0.417 \\
\hline Observations & & 368094 \\
\hline Individuals & & 49018 \\
\hline
\end{tabular}

Note: Based on SOEP v29. 
Table 2: Life satisfaction and poverty status. Results from within fixed-effects regressions.

\begin{tabular}{|c|c|c|c|c|c|}
\hline & Whole sample & Men & Women & Age $<=60$ & Age $>60$ \\
\hline$d^{0}$ (Incidence) & $\begin{array}{c}-0.132 * * * \\
(0.015)\end{array}$ & $\begin{array}{c}-0.133 * * * \\
(0.018)\end{array}$ & $\begin{array}{c}-0.133 * * * \\
(0.021)\end{array}$ & $\begin{array}{c}-0.169 * * * \\
(0.018)\end{array}$ & $\begin{array}{l}-0.024 \\
(0.028)\end{array}$ \\
\hline$d^{1}$ (Intensity) & $\begin{array}{c}-0.498 * * * \\
(0.048)\end{array}$ & $\begin{array}{c}-0.529 * * * \\
(0.058)\end{array}$ & $\begin{array}{c}-0.453 * * * \\
(0.072)\end{array}$ & $\begin{array}{c}-0.379 * * * \\
(0.054)\end{array}$ & $\begin{array}{c}-0.798 * * * \\
(0.105)\end{array}$ \\
\hline Employed & $\begin{array}{c}0.104^{* * *} \\
(0.009)\end{array}$ & $\begin{array}{c}0.056^{* * *} \\
(0.011)\end{array}$ & $\begin{array}{c}0.171 * * * \\
(0.013)\end{array}$ & $\begin{array}{c}0.150^{* * *} \\
(0.010)\end{array}$ & $\begin{array}{c}-0.047^{* *} \\
(0.018)\end{array}$ \\
\hline Age: $16-20$ & $\begin{array}{c}0.100 * * * \\
(0.029)\end{array}$ & $\begin{array}{l}-0.030 \\
(0.040)\end{array}$ & $\begin{array}{c}0.244^{* * *} \\
(0.040)\end{array}$ & $\begin{array}{c}0.180^{* * * *} \\
(0.030)\end{array}$ & \\
\hline Age: $21-30$ & $\begin{array}{l}-0.025 \\
(0.019)\end{array}$ & $\begin{array}{c}-0.057 * * \\
(0.026)\end{array}$ & $\begin{array}{c}0.008 \\
(0.026)\end{array}$ & $\begin{array}{c}0.033 \\
(0.020)\end{array}$ & \\
\hline Age: $31-40$ & $\begin{array}{l}-0.010 \\
(0.012)\end{array}$ & $\begin{array}{c}-0.043 * * * \\
(0.016)\end{array}$ & $\begin{array}{c}0.028 * \\
(0.016)\end{array}$ & $\begin{array}{c}0.019 \\
(0.012)\end{array}$ & \\
\hline Age: 51-60 & $\begin{array}{l}0.022^{*} \\
(0.013)\end{array}$ & $\begin{array}{c}0.049 * * * \\
(0.017)\end{array}$ & $\begin{array}{l}-0.013 \\
(0.017)\end{array}$ & $\begin{array}{l}-0.011 \\
(0.013)\end{array}$ & \\
\hline Age: $61-70$ & $\begin{array}{c}0.269 * * * \\
(0.020)\end{array}$ & $\begin{array}{c}0.280 * * * \\
(0.027)\end{array}$ & $\begin{array}{c}0.255^{* * *} \\
(0.027)\end{array}$ & & $\begin{array}{c}0.215 * * * \\
(0.036)\end{array}$ \\
\hline Age: 71-80 & $\begin{array}{c}0.129 * * * \\
(0.027)\end{array}$ & $\begin{array}{c}0.180 * * * \\
(0.038)\end{array}$ & $\begin{array}{c}0.073^{*} \\
(0.038)\end{array}$ & & $\begin{array}{c}0.203^{* * *} \\
(0.028)\end{array}$ \\
\hline Age: $80-\max$ & $\begin{array}{c}-0.225^{* * *} \\
(0.040)\end{array}$ & $\begin{array}{c}-0.155 * * * \\
(0.053)\end{array}$ & $\begin{array}{c}-0.310 * * * \\
(0.057)\end{array}$ & & \\
\hline No. Years of Education & $\begin{array}{l}0.007 * * \\
(0.003)\end{array}$ & $\begin{array}{c}0.028 * * * \\
(0.005)\end{array}$ & $\begin{array}{c}-0.016 * * * \\
(0.005)\end{array}$ & $\begin{array}{c}0.000 \\
(0.004)\end{array}$ & $\begin{array}{c}0.040 * * * \\
(0.012)\end{array}$ \\
\hline Married & $\begin{array}{c}0.144^{* * *} \\
(0.016)\end{array}$ & $\begin{array}{c}0.141^{* * *} \\
(0.022)\end{array}$ & $\begin{array}{c}0.131 * * * \\
(0.022)\end{array}$ & $\begin{array}{c}0.142^{* * *} \\
(0.017)\end{array}$ & $\begin{array}{c}0.039 \\
(0.136)\end{array}$ \\
\hline Widowed & $\begin{array}{c}-0.084 * * * \\
(0.031)\end{array}$ & $\begin{array}{l}-0.051 \\
(0.039)\end{array}$ & $\begin{array}{c}-0.170 * * * \\
(0.052)\end{array}$ & $\begin{array}{c}-0.140^{* *} \\
(0.058)\end{array}$ & $\begin{array}{l}-0.145 \\
(0.134)\end{array}$ \\
\hline Divorced & $\begin{array}{c}0.078 * * * \\
(0.025)\end{array}$ & $\begin{array}{c}0.116^{* * *} \\
(0.033)\end{array}$ & $\begin{array}{c}0.023 \\
(0.034)\end{array}$ & $\begin{array}{c}0.071^{* * *} \\
(0.026)\end{array}$ & $\begin{array}{c}0.021 \\
(0.134)\end{array}$ \\
\hline Separated & $\begin{array}{c}-0.199 * * * \\
(0.030)\end{array}$ & $\begin{array}{c}-0.101^{* *} \\
(0.041)\end{array}$ & $\begin{array}{c}-0.324 * * * \\
(0.042)\end{array}$ & $\begin{array}{c}-0.208 * * * \\
(0.031)\end{array}$ & $\begin{array}{c}-0.182 \\
(0.158)\end{array}$ \\
\hline East Germany & $\begin{array}{c}-0.298 * * * \\
(0.036)\end{array}$ & $\begin{array}{c}-0.332 * * * \\
(0.046)\end{array}$ & $\begin{array}{c}-0.245^{* * *} \\
(0.050)\end{array}$ & $\begin{array}{c}-0.288 * * * \\
(0.038)\end{array}$ & $\begin{array}{c}-0.381 * * * \\
(0.131)\end{array}$ \\
\hline No. Children in $\mathrm{HH}$ & $\begin{array}{c}0.017 * * * \\
(0.005)\end{array}$ & $\begin{array}{c}0.010 \\
(0.007)\end{array}$ & $\begin{array}{c}0.020 * * * \\
(0.007)\end{array}$ & $\begin{array}{c}0.019 * * * \\
(0.006)\end{array}$ & $\begin{array}{c}0.073 \\
(0.044)\end{array}$ \\
\hline Constant & $\begin{array}{c}7.459 * * * \\
(0.065)\end{array}$ & $\begin{array}{c}\text { 7.316*** } \\
(0.085)\end{array}$ & $\begin{array}{c}.592 * * * \\
(0.088)\end{array}$ & $\begin{array}{c}7.429 * * * \\
(0.068)\end{array}$ & $\begin{array}{c}.597 * * * \\
(0.259)\end{array}$ \\
\hline $\begin{array}{c}\text { Observations } \\
\text { Individuals } \\
\text { R-squared }\end{array}$ & $\begin{array}{c}368094 \\
49018 \\
0.02\end{array}$ & $\begin{array}{c}190877 \\
24733 \\
0.02\end{array}$ & $\begin{array}{c}177217 \\
24285 \\
0.03\end{array}$ & $\begin{array}{c}273805 \\
39222 \\
0.02\end{array}$ & $\begin{array}{c}94289 \\
15128 \\
0.04\end{array}$ \\
\hline
\end{tabular}

Notes: Robust standard errors in parentheses; * significant at 10\%; * significant at 5\%; ** significant at $1 \%$. Based on SOEP v29. 
Table 3: The scarring effect of poverty on life satisfaction. Results from fixed-effects regressions on individuals observed for at least 10 years.

\begin{tabular}{|c|c|c|c|c|c|}
\hline & Whole sample & Men & Women & Age <= 60 & Age > 60 \\
\hline \hline \multirow{3}{*}{ Past poverty } & $-0.043^{* *}$ & -0.035 & $-0.072^{* *}$ & $-0.057^{*}$ & -0.073 \\
& $(0.018)$ & $(0.025)$ & $(0.026)$ & $(0.021)$ & $(0.046)$ \\
\hline \hline Observations & 238349 & 122497 & 115852 & 179104 & 59245 \\
Individuals & 18351 & 9535 & 8816 & 15688 & 6729 \\
R-squared & 0.02 & 0.02 & 0.02 & 0.03 & 0.03 \\
\hline
\end{tabular}

Notes: Standard errors in parentheses; * significant at $10 \%$; * significant at $5 \%$; ** significant at $1 \%$; the regressions include all of the other control variables in Table 2. Based on SOEP v29.

Table4: Chronic poverty and persistence. Results from fixed-effects regressions for individuals observed for at least 10 years.

\begin{tabular}{|c|c|c|c|c|c|}
\hline & Whole sample & Men & Women & Age $<=60$ & Age $>\mathbf{6 0}$ \\
\hline \hline$d^{0}$ & $-0.101^{* *}$ & $-0.100^{* *}$ & $-0.104^{* *}$ & $-0.146^{* *}$ & -0.015 \\
& $(0.018)$ & $(0.022)$ & $(0.024)$ & $(0.020)$ & $(0.032)$ \\
\hline \multirow{2}{*}{$d^{1}$} & $-0.571^{* *}$ & $-0.564^{* *}$ & $-0.592^{* *}$ & $-0.441^{* *}$ & $-0.858^{* *}$ \\
& $(0.059)$ & $(0.073)$ & $(0.083)$ & $(0.061)$ & $(0.107)$ \\
\hline L.Foster $^{0}$ & $-0.074^{* *}$ & -0.042 & $-0.117^{*}$ & $-0.086^{*}$ & -0.087 \\
& $(0.034)$ & $(0.041)$ & $(0.048)$ & $(0.039)$ & $(0.072)$ \\
\hline \multirow{2}{*}{ L.(Foster ${ }^{0}-$ BCD $\left.^{0}\right)$} & $0.131+$ & $0.256^{* *}$ & 0.058 & $0.208^{* *}$ & -0.041 \\
& $(0.061)$ & $(0.073)$ & $(0.077)$ & $(0.73)$ & $(0.120)$ \\
\hline \hline Observations & 249184 & 130722 & 118462 & 182448 & 66736 \\
Individuals & 18522 & 9665 & 8857 & 15559 & 7050 \\
R-squared & 0.03 & 0.03 & 0.04 & 0.04 & 0.03 \\
\hline
\end{tabular}

Notes: Standard errors in parentheses; * significant at $10 \%$; * significant at $5 \%$; *** significant at $1 \%$; the regressions include all of the other control variables in Table 2. Based on SOEP v29. 
Table 5: The main results with different poverty lines.

\begin{tabular}{|c|c|c|c|c|c|}
\hline & \multicolumn{5}{|c|}{ Poverty line } \\
\hline & & $\begin{array}{l}40 \% \text { of } \\
\text { median }\end{array}$ & $\begin{array}{l}50 \% \text { of } \\
\text { median }\end{array}$ & $\begin{array}{l}70 \% \text { of } \\
\text { median }\end{array}$ & $\begin{array}{l}\mathbf{8 0 \%} \text { of } \\
\text { median }\end{array}$ \\
\hline \multicolumn{6}{|c|}{ Scarring (cf. Table 3) } \\
\hline Overall & Past poverty & -.006 & $-.036^{*}$ & $-.038 * *$ & $-.051 * * *$ \\
\hline Men & Past poverty & -.004 & $-.049 *$ & -.023 & -.011 \\
\hline Women & Past poverty & -.029 & -.031 & $-.064 * *$ & $-.100 * * *$ \\
\hline Age $<=60$ & Past poverty & -.009 & -.034 & $-.061 * * *$ & $-.071 * * *$ \\
\hline Age $>60$ & Past poverty & -.008 & -.011 & .019 & -.017 \\
\hline \multicolumn{6}{|c|}{ Chronic Poverty and Persistence (cf. Table 4) } \\
\hline \multirow[t]{2}{*}{ Overall } & L.Foster & $-.111 *$ & $-.085 *$ & $-.064 * *$ & -.038 \\
\hline & L. (Foster-BCD) & .053 & .080 & .040 & .062 \\
\hline \multirow[t]{2}{*}{ Men } & L.Foster & -.102 & -.080 & -.041 & -.008 \\
\hline & L. (Foster-BCD) & .120 & $.173^{*}$ & $.111^{*}$ & .004 \\
\hline \multirow[t]{2}{*}{ Women } & L.Foster & -.117 & -.084 & $-.088^{*}$ & $-.068 * *$ \\
\hline & L. (Foster-BCD) & -.100 & .086 & .054 & -.135 \\
\hline \multirow[t]{2}{*}{ Age $<=60$} & L.Foster & $-.254 * * *$ & $-.145 * * *$ & -.048 & -.029 \\
\hline & L. (Foster-BCD) & .160 & $.181 *$ & .053 & -.030 \\
\hline \multirow[t]{2}{*}{ Age $>60$} & L.Foster & .144 & -.031 & $-.104 *$ & -.087 \\
\hline & L. (Foster-BCD) & .039 & .114 & .012 & .071 \\
\hline
\end{tabular}

Notes: * significant at $10 \%$; ** significant at 5\%;** significant at $1 \%$. Based on SOEP v29. 